\title{
A comparative study on radio frequency identification system and its various applications
}

\author{
Muhammad Baballe Ahmad ${ }^{1}$, Fatima Alkasim Nababa ${ }^{2}$ \\ ${ }^{1}$ Department of Computer Engineering Technology, Kano State Polytechnic, Kano, Nigeria \\ ${ }^{2}$ Department of Computer Science, Yusuf Maitama Sule University, Kano, Nigeria
}

\section{Article Info \\ Article history: \\ Received Mar 2, 2021 \\ Revised Jun 28, 2021 \\ Accepted Jul 23, 2021}

\section{Keywords:}

Arduino

Desktop computer

Detection

RFID readers

RFID system

RFID tags

\begin{abstract}
The radio frequency identification (RFID), is a wireless technology system that is used for identifying an individual or objects through the means of radio waves that transfer information from an electronic tag, called an RFID tag. RFID consists of two main components the interrogator and the transponder. The Interrogator, which is the RFID reader, the interrogator usually transmits and receives the signal while the transponder that is the tag, is attached to the object. In the RFID system, an RFID reader interrogates the RFID tags. This tag reader generates a radio frequency interrogation, which communicates with the tags been registered in the system. This reader likewise has a receiver that captures a reply signal generated from the tags and decodes the signal. This reply signal from the tags reflects the tag's information content. Each tag of the employee or student consists of a unique identity, identification card (ID) that is assigned to a single employee or student ID card, which is recorded, in the database of the system. This research reviews some recent designs and implementation of internet of things (IoT) attendance systems using the concept of the RFID system. The analysis found that the RFID system is a very advanced technology for an automatic attendance system in an institution, organization or university, and it provides a very higher performance and accuracy than the traditional paper-based system that the employees or students normally used to sign. The use of the RFID technology enables the institution, authorities, or management to evade attendance documents from damages such as misplacement, tear, or even got lost. A combination of the model is needed which will confirm higher security, better performance, and consistency of the system.
\end{abstract}

This is an open access article under the CC BY-SA license.

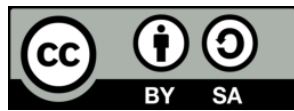

\section{Corresponding Author:}

Muhammad Baballe Ahmad

Department of Computer Engineering Technology

Kano State Polytechnic

Kano, Kano State, Nigeria

Email: mbaballe@kanopoly.edu.ng, sadiqbaballe@gmail.com

\section{INTRODUCTION}

The radio frequency identification (RFID) technology has been using for several years. The groundwork of this method was laid in the 1940s and was deployed by a British army to help in identifying an enemy aircraft [1]-[4]. Further, in 1945 Leon Theremin designed a surveillance tool for the Soviet union that help in transmitting radio waves that contain audio information. This tool has a diaphragm, which is vibrated due to sound waves, which alter the shape of the resonator. However, this device was not an identification tag but was a sneaky listening device, and therefore it was considered as a prototype of the 
RFID technology because the device was acting as a passive device that was energized by electromagnetic waves (EM) generated by an external source [5]. Likewise, in 1915, identification-of-friend-or-foe (IFF) transponder was designed to help in identifying the aircraft in World War II. Further, in 1948, Harry Stockman explored the RFID technology in his paper titled "Communication employing reflected power". In the late 1960 s, the nuclear material safety and security issue cause the further development of RFID, like the invention of the compact disc, which was visualized in the 1960s but did not get enough popularity until the 1980s. In 1973, Mario Cardullo claimed that his passive radio transponder with memory was the first true predecessor of today's RFID system [6]. Further, in 1973 the first demonstration of the RFID tags was done at the Los Alamos Scientific Laboratory [7].

The major progress in RFID tracking was done in the 1980s and 1990s. The compaq computer started using the RFID to track components through production assembly in the 1980s. The developments in the compactness of chips and improvement in the computer speed with complex topologies of computer networks have broadly contributed to the increasing momentum of the RFID system. Most significantly, the standards are benchmarked during this development epoch to ensure that users can enjoy the ease of function and compatibility of this technology [8]. The awaiting storms of potentially distracting technology have found ways to bring comfort in our lives using the evolution of technology in different ways. Smart tags are interchangeable monikers for this technology. This modern technology is what we refer to as RFID technology.

The RFID tag is usually contained within or fixed on a person or product for the identification, detection, and traceability purpose using radio waves. The RFID reader can read the data that is stored in the radio RFID tags. Our privacy can be achieved by the use of this modern technology that marks an impact on our personal lives nowadays. The RFID technology is an emergent technology that is used in a wide range of applications, it is a member of the family of automatic identification and data capture which is referred to as automatic identification and data capture (AIDC) technologies. This is the fastest and reliable means or method of identifying an object or thing. The RFID consists of two main components the interrogator, which is referred to as the RFID reader, and the transponder which is referred to as the RFID tag. The interrogator, which is the RFID reader, usually transmits and receives the signal while the transponder the RFID tag is attached to the object. In the RFID system, an RFID reader interrogates the RFID tags. This tag reader generates a radio frequency interrogation, which communicates with the tags been registered in the system. This reader likewise has a receiver that captures a reply signal generated from the tags and decodes the signal. This reply signal from the tags reflects the tag's information content. An RFID tag usually consists of an antenna and a tiny microchip [1]. The RFID alone has various applications but when it is combined with an Arduino it limitations magnify more.

The developments in RFID technology continue to produce larger memory capacities, faster processing, and wider reading ranges. They are a high tendency that the technology can replace barcode even with the expected reduction in raw materials together with economies of scale; the integrated circuit (IC) in a radio frequency (RF) tag can never be as expensive as a bar code label. Nevertheless, RFID will continue to rise in its recognized places where the barcode or other optical technologies are less effective. Attendance or daily register of employees or students in an institution organization, or places of work has turned into a vivacious assessment viewpoint in the current scheme in both institutions, organizations, schools, and universities. The unoriginal attendance-monitoring scheme has a few obstructions with the development of the latest technology gap. For example, giving out the everyday attendance sheet to a gigantic amount of employees, students in a class or an organization, industries, and places of work is extremely risky and it hinders the consideration of the students or people in that particular class or organization [2]. This is considered a waste of time and energy as well as students or individuals can intentionally register individuals who are not present in the class or places of work in the attendance sheet. If the lecturer or organization mistakenly loses these documents, all the important attendance records will be lost without hesitation. The RFID novelty has a great chore to carry out in the completion of the vision of connecting objects around us to the internet. These items extend from huge structures, planes, modern plants, vehicles, any sort of merchandise, and explicit pieces of a bigger framework to people, animals, plants, and even obvious body portions of them. The idea driving all this is called the internet of things (IoT) [3].

\section{RADIO FREQUENCY IDENTIFICATION}

RFID operates by transferring and receiving a signal using antenna and IC as shown in Figure 1. It has mainly two parts namely, the RFID tag and the RFID reader. The RFID tags contain an IC and an antenna, which is used to transmit data to the RFID reader also known as an interrogator. This reader then converts the radio waves to a more usable form of information. The data collected from the RFID tags is then 
transferred through a communications interface to a host computer system, where the information can be stored in a database and analyzed later. Figures 1-4 illustrates the information.

The RFID tags called the transponder unit could be passive or active RFID depending on the asset type and its use as shown in Figure 2. The active RFID tags usually contain a battery, a beacon to be charge periodically. Depending on the type and power of the antenna and noise in the surrounding environment, the RFID tags could be read remotely from a distance of several hundred feet. In the case of passive RFID tags, they derive their power while they are inside the signal range of the reader. Since they are substantially less expensive than the active RFID tags, they have noticeably less read rangeability. The RFID tag is an electronic tag that exchanges data with an RFID reader through radio waves as shown in Figure 3. Almost all the RFID tags have mainly two parts namely, the antenna and IC. The antenna is used to receive radio frequency waves and the IC is used in the processing and store of information. The microchip on the RFID tags is written with whatever information the user wants it. These RFID tags can operate in three different ways: a) The frequency that operates within the range of $100 \mathrm{kHz}$ to $500 \mathrm{kHz}$ is known as low radio frequency (LRF) tag; b) The frequency that operates within the range of $10 \mathrm{MHz}$ to $15 \mathrm{MHz}$ and $850 \mathrm{MHz}$ to $950 \mathrm{MHz}$ is referred to as the high radio frequency (HRF) tag; and c) The frequency that operates within the range of $2.4 \mathrm{GHz}$ to $5.8 \mathrm{GHz}$ is known as ultra-high radio frequency (UHRF) tag. LRF tags are usually economical and have slow speed as compared to HRF tags, LRF tags are usually used for applications where the data transfer over a short distance is required. The HRF tags can be used for medium-range applications having faster speed and can be used to transfer the data over a long distance. The UHRF tags are fastest than both the low radio frequency and high radio frequency tags.

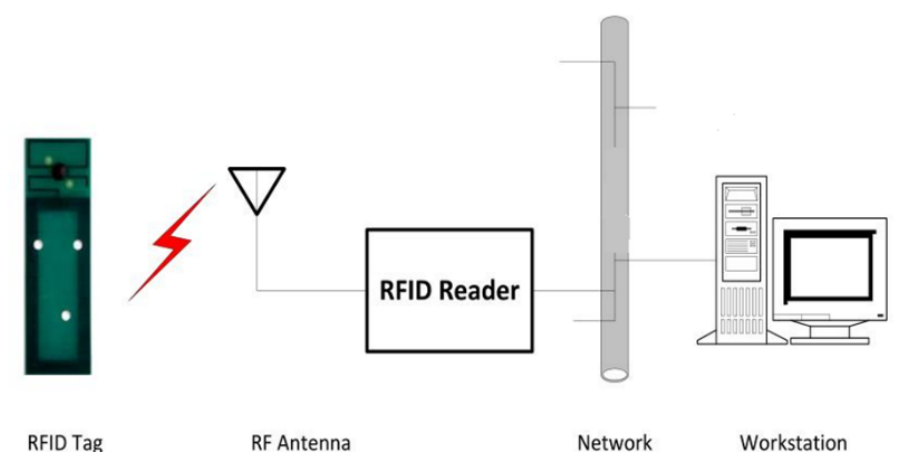

Figure 1. Working operation of the RFID components

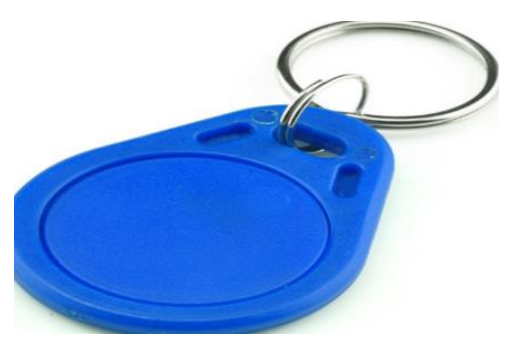

Figure 2. RFID tag

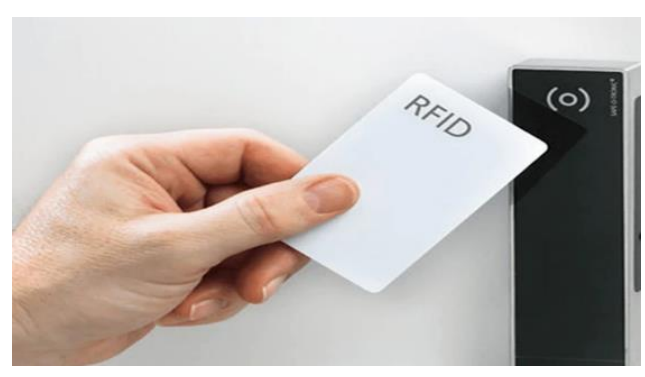

Figure 3. The RFID tag is in working mode

\subsection{RFID reader}

The RFID reader is the brain of the RFID system and is necessary for any system to function as shown in Figure 4. The readers also called the interrogators, are devices that transmit and receive radio waves to communicate with the RFID tags. The RFID reader is a device, which is used to gather information from the radio RFID system. The RFID system uses radio waves to transfer the data from the RFID tag to the RFID reader as shown in Figure 5. 


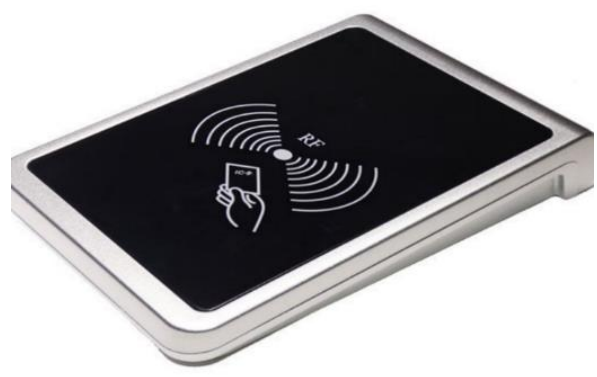

Figure 4. RFID reader

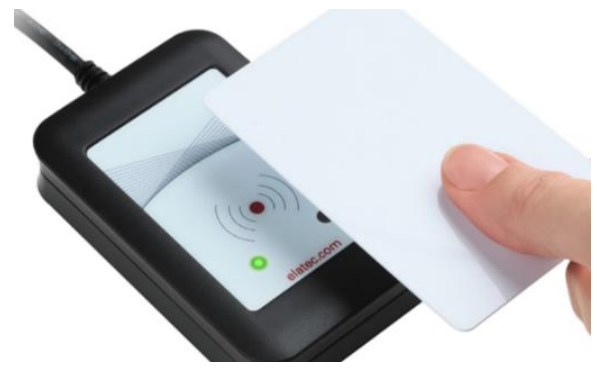

Figure 5. RFID reader in working mode

\section{THE VARIOUS APPLICATIONS OF USING A RFID SYSTEM}

Designed and implementation of a wireless fingerprint-based attendance system to obtain and record the attendance information using fingerprints known as biometric [9]. Designing time management and access monitoring system using a microprocessor card to monitor students and staff's movement with the data that are kept in the database for administrator reference in campus, office, or a certain area. Headmasters, teachers, and parents could access all the information captured by this system by fully utilizing Mykad features via the internet and intranet facilities [10]. A system that was capable to record students' attendance using interactive input, viewing students' and lecturer profiles, generating reports, and providing students with timetables the system records the attendance using a barcode scanner is designed [11]. In another spectrum, an RFID technology for checking in and checking out at parking areas without the need to stop the cars and it avoids traffic jams during the parking hours. This type of system is usually used in identifying vehicles through internet facilities by comparing the previous data in the database [12].

A system called the RFID-based automatic attendance system was developed. The attendance system software is developed using visual basic .NET (VB.NET) and database (Microsoft Access). Each of the employees or students has an RFID tag attached with the identification (ID) card. There is a serial connection between the computer and the RFID reader and the computer system. The RFID reader is placed at the lecture hall door or entrance door of the organization. Whenever students or employees enter the lecture hall or organization, the RFID reader reads the RFID tags and it stores all data (entry time and name) of the employee or students into the database via a serial connection and maintains the system. Here the admin of this system can view all the documents using the software interface by retrieving the data from the database without any hitches, not like the traditional system of writing names on the attendance sheet or piece of paper [13].

Design and implement an attendance system with the combination of RFID and a web-based system. This system uses the RFID tag and the RFID reader for getting the student's attendance and reading the particulars of the students. Then this reader connects with Arduino which serves as the brain of the whole research because all instruction is given from there, which then passes the RFID reader response to the web server by the use of Arduino shield, finally, the attendance of students can be stored in web server by using PHP: hypertext preprocessor (PHP) and structured query language (MySQL). The admin of the implemented system can now view all the student's documents by login into this particular web-based application and can view all the student's details registered or stored using liquid crystal display (LCD) [14]. A system that, the RFID and pose invariant face verification for an automatic attendance system. The system works under twofactor verifications. In the first step, the students need to use the RFID tag that is read by the RFID reader. If the first step is succeeded then it moves to the second step of verification, if not, the student becomes under the unrecognized category. The second step is face verification, if the face match with the particular registered in the RFID tag, then it marks the student attendance that is in the database. Missing the above readings, the system will automatically identify the fraud students. This two-factor automatic system reduces the misuse of identity theft for getting attendance because they are not registered in the system database [15].

In a student attendance management system based on RFID and fingerprint reader application, the system also works as a two-factor verification system. In the system, the RFID reader is linked with the computer and the computer has specific software that is used to measure the automatic attendance of the students which is developed by Microsoft Visual basic studio and SQL. In the first place, the entire student must register his or her RFID tag and fingerprints and it is stored in the database of the system. Once the students enter the classroom, they need to use the RFID tag and this will be read by the RFID reader which will then check the database of the system to check if the tag is registered, if it is registered or correct then he moves to the next verification step. In the second step, the fingerprint of the student is then verified. If it matched the information of the students registered, he or she then the attendance of the student will be stored

A comparative study on radio frequency identification (RFID) system and ... (Muhammad Baballe Ahmad) 
on the server. Besides, the lecturers or teachers have authentication to use the system, they can also act as admin of the entire system [16]. A secure digital (SD) card module with an RFID tag, which carries different voice codes, is used in the system development. The tag identification card and the code of the voice greeting are stored in the SD card module. When the student enters the classroom door, his or her RFID tag is being read. If the identification card of the student tag matched with the stored data in the SD card, then the particulars of the student or person need to use the voice greeting if it matches then the door will be open and the attendance of the student will be store in the excel sheet. The student can view their attendance detail using the LCD use in the research. In the research, the Arduino connects the liquid crystal display, the RFID reader, the SD card module, and the rest components use in the research. Likewise, the system has very simple schematics than another system because of the very simple components uses and the design of the whole system. Also, you can we get fast responses and accurate results [17].

A model system called the microcontroller-based attendance system using the RFID system and global system for mobile (GSM) was designed. The system consists of three ATmega16 microcontrollers placed in between the RFID reader, global system for mobile modem, and the computer. Each of the microcontrollers' uses has its purpose. The system will start whenever a lecturer or teacher used his or her RFID tag to enter the lecture room or classroom then the students will enter the classroom also by swapping their RFID tags within five minutes. The RFID reader reads the RFID tag, sends the signal to the first microcontroller, which will analyze the signal of the RFID reader, and opens the classroom door using infrared rays (IR) signal, which is influenced by a motor. This signal is temporarily stored in the microcontroller, when the lecturer or teacher finishes his or her class, he or she must swap the RFID tag again to the RFID reader and the system will decide automatically that the class is finished. Therefore, the microcontroller will pass the temporarily stored signal to the computer database as the attendance. In case if a student is absent, the signal will pass it to the global system for mobile, modem and it will send this message to the parents of the students who were not present during the lectures or lesson in the lecture room or the classroom. If any of the students go out before the lecturer or teacher, the system will not count the student present in the lecture room or classroom. The system itself is an added advantage and a reliable security system. Thus, the students cannot cheat the administration and their parents [18]. A system that will work with the RFID technology and global system for mobile. In their research, they used a microcontroller as a midway among global systems for mobile modules and RFID technology. Whenever the students enter the lecture room or classroom, they need to make use of their tag, which is read by the RFID reader, and it sends it to the global system for the mobile module. If the identification card of the student or individual tag does not match with the stored information of the database he or she is considered as an unapproved person. If it accepts the tag, then the global system for the mobile module will send a message to the administration and their parents that the students attended lectures or lessons [19].

A system that uses web-based attendance using four-tier architecture by the use of RFID and biometrics. In their system, the students, lecturers, or teachers' RFID has a unique code, which will be stored in the database of the institution or school. The RFID reader and the fingerprint device are placed at the entrance door of the lecture room or classroom. Whenever the students want to enter the classroom, they need to use the RFID tag which will be read by an RFID reader and validate the identity of the students by comparing it with the information stored in the database whether the tag matches or not. The second stage of verification will be allowed if and only if the first stage of verification is succeeded. The verification with the fingerprint is the second stage of the system and if the student's fingerprint matches with the data in the database, then the attendance will be marked and stored into the database, but if he or her record does not store or captured in the database then they will be no attendance for that student. The fingerprint verification is merely acting in ten minutes including five minutes before the schedule and after the schedule of class starting time. If anyone is late then it will deny providing attendance to that particular student that is late but the students can stay at the lectures and learn but will not have attendance for that class. Lastly, a short message service (SMS) will be sent to the students' parents if the students are present or not in the lecture room or classroom [20].

Prototype of the attendance management system with the placement of a bigger number of RFID readers placed in the room and there is a server application maintained through a laptop. The radio frequency identification reader and the laptop or personal computer (PC) are connected with the help of a wireless router or local area network (LAN) connection. Whenever a student or person enters the classroom or lecture room, he or she needs to use the RFID tag which is read by the RFID reader and passes the student's attendance to the server through wireless or LAN connection. Since many of the RFID readers are placed, more than one person can get the attendance simultaneously and get the higher efficiency than the traditional method or using the single radio frequency identification reader [16]. In addition, proposed a system that is working with the RFID technology and Telegram messenger application. In their system, the students need to meet their lecturers or teachers for the tapping of their RFID tags. If the tags match with tag information 
stored in the database, then it will send the attendance to the management of the institution or principal in the form of an excel sheet as well as send a message to the specific student's parent via Telegram messenger. Meanwhile, facial verification cost is comparably average to other biometric verification. It also could be considered for a better system for developing an automatic attendance system.

The RFID technology with a fingerprint system is very comparable to the RFID with the facial system. Each characteristic of the table is providing similar ideas except for their cost. Fingerprint biometric systems provide a very lower cost compared to the retina and iris. Meanwhile, software, which makes use of visual studio and SQL, are costs in a great measure. Eventually, the system is considered a high-cost system with a higher eminence [17]. A low-cost portable smartcard-based attendance system is the combination of RFID with fingerprint biometric technology to enhance the safety level and integrity of the records. This design system does not merely make the system design simpler but likewise improves the efficiency of the institution both in terms of manpower and time. This system does not merely abridge the method of taking attendance but decreases the rate of errors and permits for faster verification of student attendance, all with minimal human interaction [18]. Smart attendance monitoring system (SAMS) is a face recognition-based attendance system for classroom environment. This system is developed by the integration of omnipresent components to make a portable device for managing the student's attendance using face recognition technology [19]. A radio frequency identification-based attendance system with SMS backup. This project seeks to address means of automatically registering the student's recording attendance, saving students information on the PC as well as backing their information via the global system for mobile communication and finally making a decision on the worthiness of a student to sit for an examination course or attending the lectures [20].

In summary, the various applications of using an RFID system are:

a. RFID can be used in various environments, this includes livestock, military, and scientific areas, and also in tertiary institutions or organizations to prevent unnecessary intrusions by the students or individuals.

b. RFID can be used in addition to barcode. These two technologies can be complementing each other. With the combinations of such technologies, one can hardly enter secure environments or institutions.

c. Unattended operations are possible, minimizing human errors and high costs.

d. RFID can help in identifying moving objects or elements that have tags embedded in them.

e. RFID. can cover a larger area of coverage, up to several feet.

f. RFID system is used for access management.

g. RFID system is used in the tracking of goods.

h. RFID is used in the tracking of persons and animals.

i. $\quad$ RFID is used in tax collection and contactless payment

j. RFID system is used as a machine in reading travel documents.

k. RFID is used in airport baggage tracking logistics.

1. RFID is used in passports development.

m. RFID is used for medicine and drugs record.

n. RFID tags are used in clothing, e.g. in jeans, shirts, coats, and trousers

\section{CONCLUSION}

In this paper, many papers related to the RFID system were review, and we have seen their various improvements in technologies and the need of using the RFID system over the traditional paper-based attendance sheet, which has been used over several years, and its various areas of applications.

\section{REFERENCES}

1. E. Orji, C. Oleka, U. I. Nduanya, "Automatic Access Control System using Arduino and RFID," Journal of Scientific and Engineering Research, vol. 5, no. 4, pp. 333-340, 2018. [Online] Available: http://jsaer.com/download/vol-5-iss-4-2018/JSAER2018-05-04-333-340.pdf

2. K. Vandana, K. Anil Kumar, G. Sivani, G. Devanand, E. Venkatanarayana, "Examination Room Guidance System Using RFID and Arduino," International Research Journal of Engineering and Technology (IRJET), vol. 5, no. 4, pp. 642-645, Apr. 2018. [Online] Available: https://www.irjet.net/archives/V5/i4/IRJET-V5I4142.pdf

3. M. Cavas and M. A. Baballe, "A Review Advancement of Security Alarm System Using Internet of Things (IoT)," International Journal of New Computer Architectures and their Applications, vol. 9, no. 2, pp. 38-49, Nov. 2019, doi: 10.17781/P002617.

4. Z. Yongqiang and L. Ji, "The Design of Wireless Fingerprint Attendance System," 2006 International Conference on Communication Technology, 2006, pp. 1-4, doi: 10.1109/ICCT.2006.341990.

5. M. Man and L. Y. Kyng, "Utilizing MYKAD Touch N Go features for Student Attendance System (TITO)," Proceeding of 1st International Malaysian Educational Technology Convention, Nov. 2007, pp.114-120. 
6. J. Sidi, S. N. Junaini, and L. S. Ling, "ISAMS: Tracking Student Attendance Using Interactive Student Attendance Management System," Proceedings of the 3rd Malaysian Software Engineering Conference, Dec. 2007, pp. 218223.

7. Z. Pala and N. Inanc, "Smart Parking Applications Using RFID Technology," 2007 1st Annual RFID Eurasia, Sep. 2007, pp. 1-3, doi: 10.1109/RFIDEURASIA.2007.4368108.

8. A. A. Olanipekun and O. Boyinbode, "An RFID-Based Automatic Attendance System in Educational Institutions of Nigeria," International Journal of Smart Home, vol. 9, no. 12, pp. 65-74, Dec. 2015, doi: 10.14257/ijsh.2015.9.12.07.

9. H. D. Rjeib, N. S. Ali, A. Al Farawn, B. Al-Sadawi, and H. Alsharqi, "Attendance and Information System using RFID and Web-Based Application for Academic Sector," International Journal of Advanced Computer Science and Applications (IJACSA), vol. 9, no. 1, pp. 266-274, 2018, doi: 10.14569/IJACSA.2018.090137.

10. S. Pss and M. Bhaskar, "RFID and Pose Invariant Face Verification Based Automated Classroom Attendance System," 2016 International Conference on Microelectronics, Computing and Communications (MicroCom), 2016, pp. 1-6, doi: 10.1109/MicroCom.2016.7522434.

11. M. M. M. Thein, C. M. New, and H. M. Tun, "Students' Attendance Management System Based on RFID and Fingerprint Reader," International Journal of Scientific \& Technology Research, vol. 4, no. 7, pp. 30-38, Jul. 2015.

12. Y. Mishra, G. K. Marwah, and S. Verma, "Arduino Based Smart RFID Security and Attendance System with Audio Acknowledgement," International Journal of Engineering Research \& Technology (IJERT), vol. 4, no. 1, pp. 363$367,2015$.

13. A. K. Shukla, "Microcontroller Based Attendance System Using RFID and GSM," International Journal of Emerging Technologies in Engineering Research (IJETER), vol. 5, no. 8, pp. 127-131, 2017. [Online] Available: https://www.ijeter.everscience.org/Manuscripts/Volume-5/Issue-8/Vol-5-issue-8-M-21.pdf

14. S. Konatham, B. S. Chalasani, N. Kulkarni and T. El Taeib, "Attendance Generating System Using RFID and GSM," 2016 IEEE Long Island Systems, Applications and Technology Conference (LISAT), 2016, pp. 1-3, doi: 10.1109/LISAT.2016.7494157.

15. R. Roy, "A Web Enabled Secured System Designed for Attendance Monitoring Applying Biometric and Radio Frequency Identification (RFID) Technology," 2014 International Conference on Signal Propagation and Computer Technology (ICSPCT 2014), 2014, pp. 653-657.

16. T. Sanjay, "Attendance Management System," International Journal of Emerging Technology and Advanced Engineering, vol. 4, no. 7, pp. 541-543, 2014.

17. M. B. Chaniago and A. Junaidi, "Student Presence Using RFID and Telegram Messenger Application," 8th Widyatama International Seminaron Sustainability (WISS 2016), 2016.

18. V. M. Vinod, G. Murugesan, V. Mekala, S. Thokaiandal, M. Vishnudevi, and S. M. Siddharth, "A Low-Cost Portable Smart Card Based Attendance System," IOP Conference Series: Materials Science and Engineering, 2021, vol. 1012, p. 012046, doi: 10.1088/1757-899X/1012/1/012046.

19. S. Bhattacharya, G. S. Nainala, P. Das and A. Routray, "Smart Attendance Monitoring System (SAMS): A Face Recognition Based Attendance System for Classroom Environment," 2018 IEEE 18th International Conference on Advanced Learning Technologies (ICALT), 2018, pp. 358-360, doi: 10.1109/ICALT.2018.00090.

20. U. K. Nkalo, E. O. Agwu, and E. C. Stanley, "Radio Frequency Identification (RFID) Based Attendance System with Short Message Service (SMS) Backup," IOSR Journal of Computer Engineering (IOSR-JCE), vol. 21, no. 2, pp. 1-8, 2019, doi: 10.9790/0661-2102010108. 